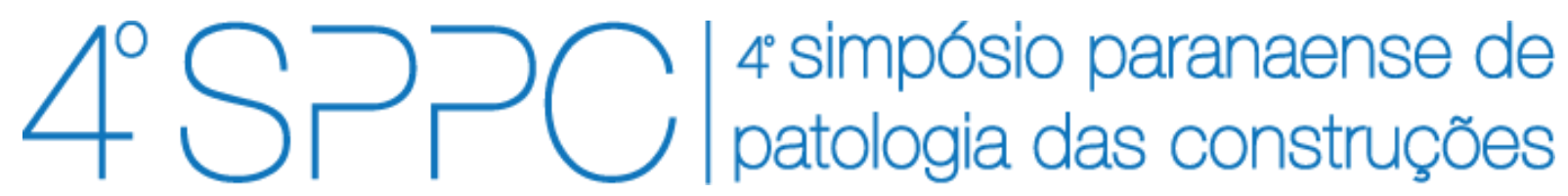

ISSN 2526-7248 artigo n. 4SPPC125, pp. 234-242, 2019

\title{
Estudo teórico-experimental da resistência de pilares sob flexão composta normal
}

Muniz, Mara Bruna Silveira 1; Silva Júnior, Francisco Eudázio Suriano da 2; Siqueira, Gladstone Araújo ${ }^{3}$; Silva, Ricardo José Carvalho ${ }^{4}$

${ }^{1}$ Engenheira Civil mestranda em Engenharia Oceânica, Universidade Federal de Rio Grande, mbrunamuniz@gmail.com

${ }^{2}$ Engenheiro Civil mestrando em Modelagem Computacional, Universidade Federal de Rio Grande, jrsuri@outlook.com

${ }^{3}$ Engenheiro Civil, Universidade Estadual Vale do Acaraú, gladstonesiqueira@hotmail.com

${ }^{4}$ Professor doutor da Universidade Estadual Vale do Acaraú, ricardo.carvalho222@gmail.com

Resumo: A flexão composta normal ocorre quando a resultante das tensões normais que agem sobre uma seção transversal pode ser decomposta em uma força normal e um momento fletor. Esse fenômeno é resultante do carregamento na seção transversal de um elemento estrutural de forma excêntrica, sendo esse aplicado em um dos eixos principais de inércia da peça. Dessa forma, para melhor entender o comportamento das estruturas de concreto armado solicitadas a esse fenômeno físico, optou-se em ensaiar, em laboratório, pilares reduzidos. Para isso, cinco pilares de concreto armado foram ensaiados. Buscou-se analisar a variação da resistência desses modelos experimentais de acordo com o aumento da excentricidade das cargas aplicadas em relação ao centro geométrico da seção do pilar. O momento atuante nos pilares foi quantificado e observou-se um aumento na ductilidade dos espécimes com maiores excentricidades.

Palavras-chave: flexo-compressão, excentricidade, ensaio experimental.

Abstract: The normal composed bending occurs when the resultant of the normal stresses acting on a cross section can be decomposed into a normal force and bending moment. This phenomenon results from the cross-sectional loading of an eccentric structural member, which is applied to one of the main inertia axes of the part. In order to better understand the behavior of the reinforced concrete structures requested to this physical phenomenon, it was decided to test, in the laboratory, reduced-size columns. For this, five reinforced concrete columns were tested. It was analyzed the variation of the resistance of these experimental models according to the increase of the eccentricity of the applied loads in relation to the geometric center of the section of the column. The moment in the columns was quantified and there was an increase in the ductility of the specimens with greater eccentricities.

Keywords: flexo-compression, eccentricity, experimental test. 
MUNIZ,M.B.S.; SILVA JÚNIOR,F.E.S.D.; SIQUEIRA,G.A.; SILVA,R.J.C. ESTUDO TEÓRICO-EXPERIMENTAL DA RESISTÊNCIA DE PILARES SOB FLEXÃO COMPOSTA NORMAL. $4^{\circ}$ Simpósio Paranaense de Patologia das Construções (40 SPPC), artigo 4SPPC125, pp. 234 - 242, 2019. DOI: 10.4322/2526-7248.045

\section{Introdução}

Os pilares de concreto armado são elementos lineares com superfície plana ou casca cilíndrica de eixo reto, usualmente dispostos na vertical, em que as forças normais de compressão são preponderantes, de acordo com a ABNT NBR 6118 [1].

Conforme Bastos [2], a NBR 6118 na versão de 2003 fez modificações em algumas das metodologias de cálculo das estruturas de Concreto Armado, como também em alguns parâmetros aplicados no dimensionamento e verificação das estruturas. Especial atenção é dada à questão da durabilidade das peças de concreto. Particularmente no caso dos pilares, a norma introduziu várias modificações, como no valor da excentricidade acidental, um maior cobrimento de concreto, uma nova metodologia para o cálculo da esbeltez limite relativa à consideração ou não dos momentos fletores de segunda ordem e, principalmente, com a consideração de um momento fletor mínimo, que pode substituir o momento fletor devido à excentricidade acidental. A versão de 2014 manteve essas prescrições e introduziu que a verificação do momento fletor mínimo pode ser realizada comparando uma envoltória resistente, que englobe a envoltória mínima com segunda ordem. $O$ correto dimensionamento e execução dessas peças são fundamentais para o bom funcionamento da estrutura, pois esta é encarregada de transferir as cargas das vigas provenientes da utilização das lajes para os elementos de fundação da edificação, sendo essencial para segurança e conforto dos usuários.

De acordo com Casagrande [3], o dimensionamento de pilares é uma tarefa complexa. Essas peças são sujeitas à flexão composta e a fenômenos de instabilidade como a flambagem e a efeitos cumulativos de segunda ordem. A NBR 6118 [1] ainda exige que pilares muito esbeltos sejam dimensionados considerandose o fenômeno da fluência, que também caracteriza o comportamento não-linear do concreto armado e soma-se à complexidade do processo de cálculo.

Oliveira et al. [4] analisaram a influência da locação dos pilares no deslocamento da estrutura, tendo em vista que estes elementos estruturais colaboram para a rigidez estrutural e, por conseguinte, na suscetibilidade aos efeitos globais de segunda ordem. Os autores realizaram um estudo de caso, calcularam os efeitos de segunda ordem através da NBR 6118 [1] e observaram que quando tem-se um melhor alinhamento dos pilares e vigas, a rigidez aumenta e o deslocamento é reduzido.

Alva et al. [5] estudaram a influência da rigidez das ligações viga-pilar na análise estrutural de edifícios em concreto armado. Com o auxílio do programa TQS, uma edificação foi calculada considerando ligações rígidas e ligações deformáveis, visando identificar a importância da consideração da influência da rigidez das ligações viga-pilar na estabilidade global e na redistribuição de esforços de estruturas monolíticas de concreto armado. Os autores concluiram que negligenciar a influência da rigidez das ligações viga-pilar na análise de estruturas monolíticas em concreto armado pode gerar soluções muito diferentes do comportamento real da estrutura na prática, e enfatizaram que uma modificação na rigidez das ligações altera a maneira como a estrutura se comporta com relação aos efeitos de segunda ordem, modificando o dimensionamento dos elementos estruturais pertencentes à edificação. 
MUNIZ,M.B.S.; SILVA JÚNIOR,F.E.S.D.; SIQUEIRA,G.A.; SILVA,R.J.C. ESTUDO TEÓRICO-EXPERIMENTAL DA RESISTÊNCIA DE PILARES SOB FLEXÃO COMPOSTA NORMAL. $4^{\circ}$ Simpósio Paranaense de Patologia das Construções ( $4^{\circ}$ SPPC), artigo 4SPPC125, pp. 234 - 242, 2019. DOI: 10.4322/2526-7248.045

No trabalho de Hadhood et al. [6] foram testados 10 pilares de concreto armado com seção circular e reforçados com barras e espirais de GFRP (fibras de vidro). Os pilares possuíam diferentes taxas de armadura e foram submetidos a carregamentos com diferentes excentricidades para se traçar a envoltória de falha dos pilares. E em Hales et al. [7] foi observado o comportamento carga-deflexão de pilares esbeltos de concreto armado. Um modelo analítico foi proposto para prever o comportamento de pilares esbeltos reforçados internamente com espirais de FRP (polímeros reforçados com fibras) e com barras de aço longitudinais. O modelo foi então usado para criar diagramas de interação para pilares com diferentes índices de esbeltez.

Os pilares de concreto armado são elementos estruturais que apresentam ruptura, em geral, de forma abrupta, e não dúctil como as vigas (quando corretamente dimensionadas). A presença de momentos fletores atuantes em pilares é um fator predominante na resistência dessas peças. Esses esforços são decorrentes de diversos fatores, tais como o seu desaprumo ou a adoção de sapatas de divisa sem vigas de equilíbrio, que são problemas de má gestão da qualidade e de concepção estrutural.

Portanto, objetiva-se com este trabalho quantificar a variação na ductilidade do concreto em pilares experimentais idênticos de tamanho reduzido, variando-se as excentricidades dos carregamentos. Para isto, testou-se os pilares até sua ruptura e foi observado o modo de ruptura, carregamento de ruína e fissuras visíveis.

\section{Metodologia}

O experimento foi realizado a partir do ensaio de modelos reduzidos de cinco pilares, sendo um solicitado à compressão axial centrada e os demais submetidos à flexo-compressão normal, ou seja, aplicação de cargas excêntricas ao centro de gravidade dos pilares.

Todos os ensaios foram realizados no Laboratório de Materiais e Estruturas da Universidade Estadual Vale do Acaraú - UVA. Os pilares foram produzidos com o mesmo concreto, as mesmas áreas de aço, os mesmos espaçamentos de armadura e as mesmas dimensões para seções.

O concreto utilizado foi obtido em central dosadora, e foram moldados seis corpos de prova cilíndricos de dimensões $(10 \times 20) \mathrm{cm}^{2}$, onde três corpos de prova foram submetidos a ensaio de compressão axial e os outros três ao ensaio de compressão diametral (tração). Os corpos de prova foram produzidos no mesmo dia e com o mesmo concreto das vigas.

Foram utilizadas barras de aço nervuradas CA-50 de 6,3 mm de diâmetro para as armaduras longitudinais do pilar e armaduras longitudinais e transversais dos vínculos superior e inferior. Já para as armaduras transversais do pilar foram utilizadas barras de aço CA-60 com diâmetro de 5,0 mm.

A concretagem foi realizada após ensaio de abatimento de tronco de cone, que constatou slump de $9 \mathrm{~cm}$. O concreto lançado nas fôrmas foi adensado mecanicamente por meio de um vibrador de agulha de $34 \mathrm{~mm}$ de diâmetro. 
MUNIZ,M.B.S.; SILVA JÚNIOR,F.E.S.D.; SIQUEIRA,G.A.; SILVA,R.J.C. ESTUDO TEÓRICO-EXPERIMENTAL DA RESISTÊNCIA DE PILARES SOB FLEXÃO COMPOSTA NORMAL. $4^{\circ}$ Simpósio Paranaense de Patologia das Construções (40 SPPC), artigo 4SPPC125, pp. $234-242$, 2019. DOI: 10.4322/2526-7248.045

O acabamento da superfície exposta foi feito através de colher de pedreiro, com o intuito de minimizar as imperfeições geométricas. Após a confecção das vigas e corpos de prova, a cura foi feita através de umedecimento da superfície das peças, realizado seis vezes ao dia, durante três dias. No quarto dia pós-concretagem, as peças foram submetidas à desforma e foram completamente imersas em tanques de água, onde permaneceram durante 17 dias.

O detalhamento dos pilares é mostrado nas Figuras 2 e 3.

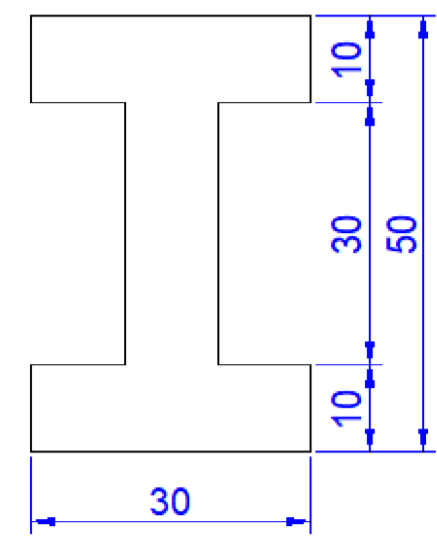

Vista frontal

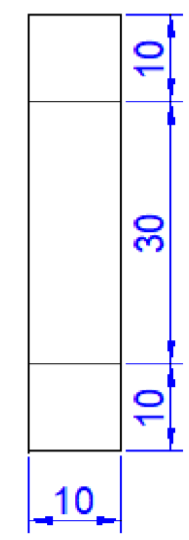

Vista lateral

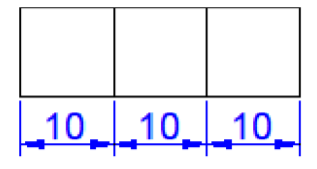

Vista superior

Figura 2: Vistas das seções dos pilares, com dimensões em centímetros
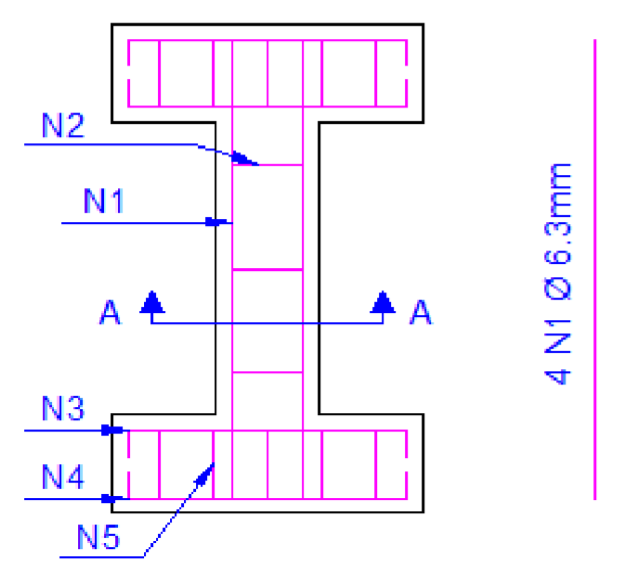

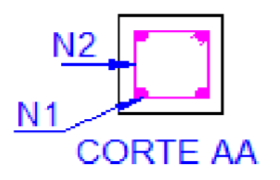

$2 \mathrm{~N} 3 \varnothing 6.3 \mathrm{~mm}$

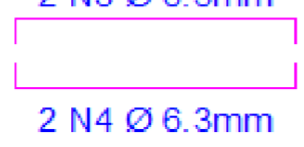

$5 \mathrm{~N} 5 \varnothing 6.3 \mathrm{~mm} \mathrm{C} / 5,5$

Figura 3: Detalhamento das armaduras 
MUNIZ,M.B.S.; SILVA JÚNIOR,F.E.S.D.; SIQUEIRA,G.A.; SILVA,R.J.C. ESTUDO TEÓRICO-EXPERIMENTAL DA RESISTÊNCIA DE PILARES SOB FLEXÃO COMPOSTA NORMAL. $4^{\circ}$ Simpósio Paranaense de Patologia das Construções (40 SPPC), artigo 4SPPC125, pp. 234 - 242, 2019. DOI: 10.4322/2526-7248.045

As cargas foram aplicadas nos pilares por uma prensa hidráulica com capacidade de carga de $120 \mathrm{tf}(\sim 1200 \mathrm{KN})$. As leituras foram realizadas através do seu painel analógico. A Fig. 4 ilustra a prensa utilizada para o ensaio.
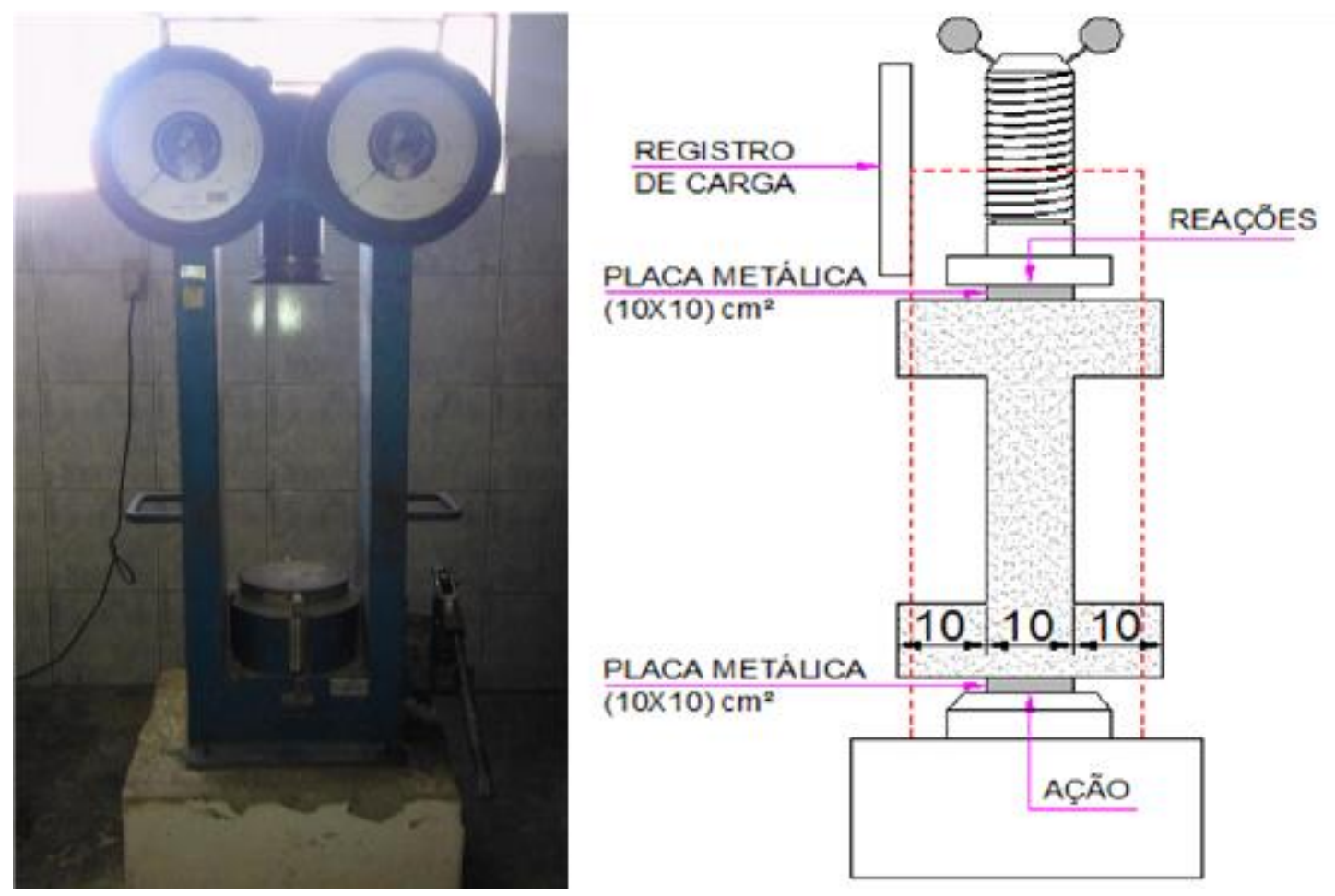

Figura 4: Prensa hidráulica e esquema do ensaio

Para obter a variação dos valores das excentricidades, utilizou-se duas placas metálicas, uma no topo e outra na base dos pilares, de $(10 \times 10) \mathrm{cm}^{2}$, onde 0 deslocamento do centroide do pilar em relação ao centroide da placa permitiu alcançar a variação desejada para cada ensaio (Fig. 5).
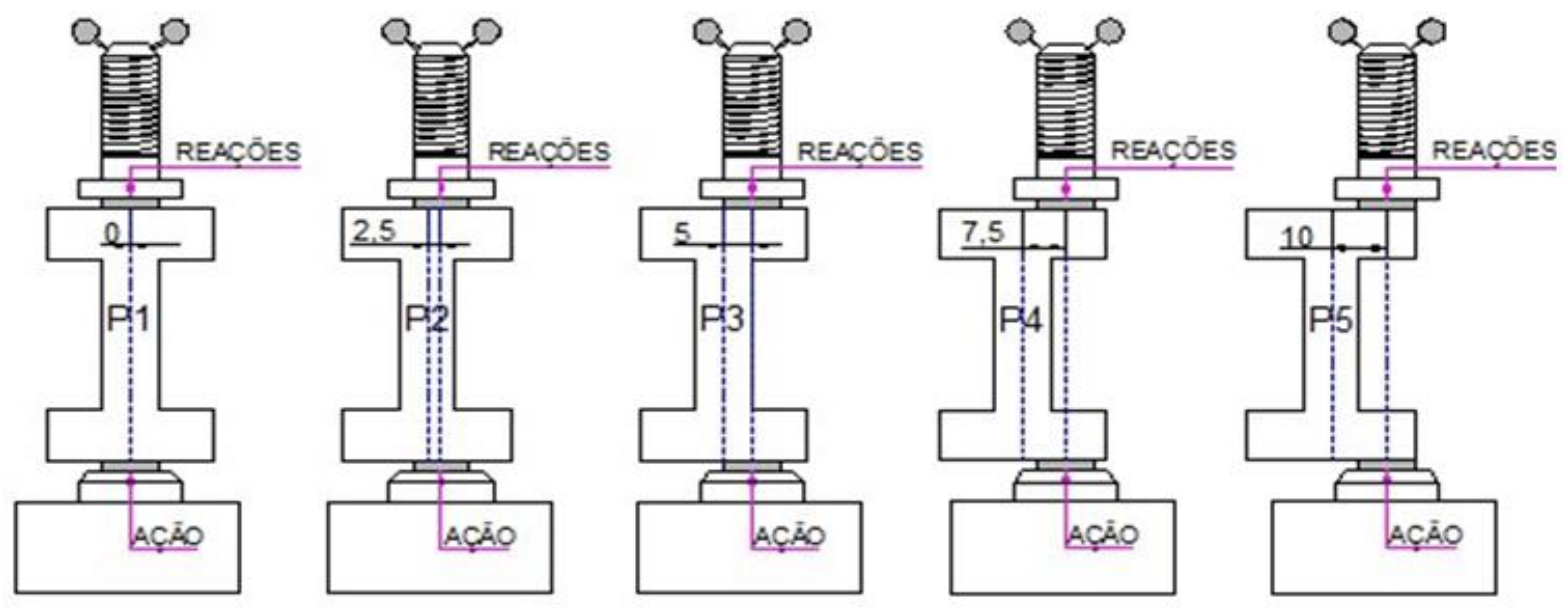

Figura 5: Detalhe do posicionamento dos pilares 
O carregamento foi aplicado em intervalos de $40 \mathrm{kN}$ para os pilares $\mathrm{P} 1$ e P2, $20 \mathrm{kN}$ para os pilares P3 e P4 e $10 \mathrm{kN}$ para o pilar P5, de forma que pudessem ser registrados o aparecimento e a evolução das fissuras.

\section{Resultados}

\subsection{Testes de resistência do concreto}

Os ensaios de resistência à compressão e tração dos corpos de prova de concreto foram realizados no dia posterior ao ensaio dos pilares e seguiram as recomendações da NBR 5739 [8] e da NBR 7222 [9]. A resistência à compressão prevista do concreto era de $30 \mathrm{MPa}$. Os resultados desses ensaios são apresentados na Tabela 1.

Tabela 1: Resultados dos ensaios dos corpos de prova

\begin{tabular}{cccc}
\hline & $\begin{array}{c}\text { Corpo de } \\
\text { prova }\end{array}$ & $\begin{array}{c}\text { Tensão de } \\
\text { ruptura (MPa) }\end{array}$ & Média (MPa) \\
\hline \multirow{2}{*}{$\begin{array}{c}\text { Compressão } \\
\text { axial }\end{array}$} & CP1 & 24,5 & \\
& CP2 & 28,2 & 28,1 \\
\hline \multirow{2}{*}{ Compressão } & CP3 & 31,5 & \\
diametral & CP4 & 3,3 & \\
& CP5 & 2,9 & 3,3 \\
\hline
\end{tabular}

Dessa forma, a média das tensões de esmagamento dos corpos de prova ensaiados à compressão axial foi de $28,1 \mathrm{MPa}$. Já a média das tensões de tração obtidas pelo ensaio de compressão diametral foi de 3,3 MPa.

\subsection{Ensaios dos pilares}

Os pilares após a ruptura são apresentados na Fig. 6 .

O pilar P1 foi submetido a um carregamento centrado aplicado em passos de carga de $40 \mathrm{kN}$. As primeiras fissuras foram analisadas quando o mesmo estava submetido a carga de $278 \mathrm{kN}$, muito próximo da sua carga de ruptura que foi 280 kN, o que caracterizou a não ductilidade desse elemento.

O pilar P2, por sua vez, foi posicionado na prensa de modo que o seu centro de gravidade (CG) estivesse $2,5 \mathrm{~cm}$ deslocado em relação ao CG da placa metálica responsável pela transferência de carga. A ruptura desse elemento ocorreu por esmagamento do concreto, com carga de ruptura de $200 \mathrm{kN}$. Vale ressaltar que os passos de carga permaneceram a cada $40 \mathrm{kN}$ e o surgimento das primeiras fissuras foi observado à carga de $160 \mathrm{kN}$. 
O pilar P3 foi posicionado na prensa de modo que o seu centroide estivesse $5 \mathrm{~cm}$ distante do CG da placa metálica. Devido ao aumento significativo da excentricidade da carga aplicada, os passos de carga passaram a ter intervalos a cada $20 \mathrm{kN}$.

A ruptura desse pilar ocorreu por esmagamento do concreto, com carga de ruptura registrada de $138 \mathrm{KN}$. As primeiras fissuras foram identificadas à carga de $60 \mathrm{kN}$. Essas, por sua vez, surgiram na seção longitudinal do pilar oposta à carga excêntrica, caracterizando fissuras de tração. Vale evidenciar que a formação de fissuras de tração nessa peça ocorreu de forma bem mais evidente do que nas anteriores, o que caracterizou o posicionamento da linha neutra dentro da seção do pilar ensaiado.

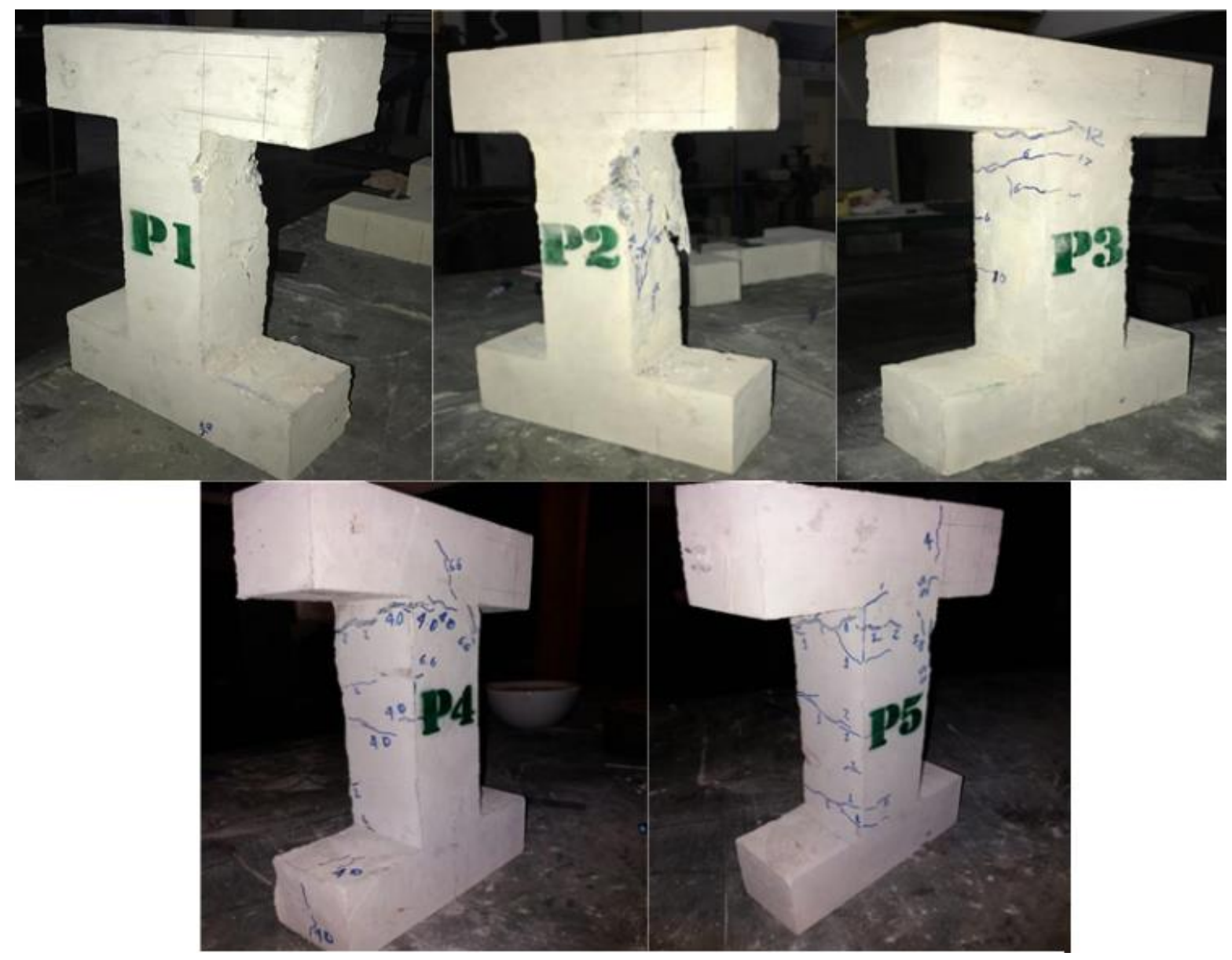

Figura 6: Pilares após a ruptura

O pilar P4 foi disposto na prensa de modo que a carga aplicada estivesse $7,5 \mathrm{~cm}$ excêntrica ao centroide desse. Os passos de carga foram mantidos de forma semelhante ao ensaio do P3, a cada $20 \mathrm{kN}$. A ruptura desse pilar ocorreu por esmagamento do concreto, apresentando carga de ruptura de $66 \mathrm{kN}$. As primeiras fissuras foram analisadas logo no primeiro passo de carga, $20 \mathrm{kN}$. Essas, de características semelhantes às primeiras fissuras analisadas do P3, são de tração, evidenciando as fibras alongadas ao longo do comprimento do pilar, posicionadas abaixo da sua linha neutra. Todavia, esse elemento apresentou mais fissuras de tração que o P3, evidenciando maior ductilidade e comportamento semelhante ao de uma viga. 
Por fim, o pilar P5 foi ensaiado de modo que o CG da carga aplicada ficou posicionado a $10 \mathrm{~cm}$ do CG do pilar, de modo que a placa metálica responsável pela distribuição de tensões estivesse totalmente fora da seção do pilar. Os passos de carga, por sua vez, foram realizados a cada $10 \mathrm{kN}$, devido ao significativo valor de excentricidade. $O$ elemento de estudo entrou em estado de ruína por esmagamento do concreto, com registro de carga de ruptura de $58 \mathrm{KN}$. Já, as primeiras fissuras surgiram ao término do primeiro intervalo de carga, a $10 \mathrm{kN}$, sendo essas de tração, pois se posicionaram na seção longitudinal oposta à carga excêntrica. No entanto, diferentemente de todos os outros pilares ensaiados, as fissuras distribuíram-se de forma relativamente simétrica ao longo da altura útil do pilar, sendo essas propagadas nos extremos do pilar, nas proximidades dos seus vínculos de ligação, e na sua altura média.

$\mathrm{Na}$ Tabela 2 são apresentadas as cargas de primeira fissura e de ruptura dos pilares.

Tabela 2: Resultados dos ensaios dos pilares

\begin{tabular}{cccccc}
\hline Pilar & $\begin{array}{c}\text { Excentricidade } \\
\mathbf{( c m )}\end{array}$ & $\mathbf{F r}^{\mathbf{1}} \mathbf{( k N )}$ & $\mathbf{F u}^{\mathbf{2}} \mathbf{( k N )}$ & $\mathbf{F r} / \mathbf{F u}$ & $\begin{array}{c}\text { Forma de } \\
\text { ruptura }\end{array}$ \\
\hline P1 & 0,0 & 278 & $\mathbf{2 8 0}$ & $99,3 \%$ & Frágil \\
P2 & 2,5 & 160 & $\mathbf{2 0 0}$ & $80,0 \%$ & Frágil \\
P3 & 5,0 & 60 & $\mathbf{1 3 8}$ & $43,5 \%$ & Dúctil \\
P4 & 7,5 & 20 & $\mathbf{6 6}$ & $30,3 \%$ & Dúctil \\
P5 & 10,0 & 10 & $\mathbf{5 8}$ & $17,2 \%$ & Dúctil \\
\hline
\end{tabular}

${ }^{1} \mathrm{Fr}=$ carregamento de primeira fissura;

${ }^{2} \mathrm{Fu}=$ carregamento de ruptura.

Verifica-se que a capacidade de carga dos pilares diminui com o aumento da excentricidade, no entanto, a ductilidade dos elementos aumenta. Entenda-se por ductilidade, para fins deste estudo, o espaço entre o carregamento de primeira fissura e o de ruptura da peça.

O pilar P1 apresentou $\mathrm{Fr} / \mathrm{Fu}$ igual a $99,3 \%$, ou seja, a primeira fissura surgiu somente com 99,3\% do carregamento. O pilar P2 apresentou $\mathrm{Fr} / \mathrm{Fu}$ de $80 \%$. Ambos os pilares, apesar de serem os mais resistentes, também foram os menos dúcteis. Já os demais pilares apresentaram $\mathrm{Fr} / \mathrm{Fu}$ abaixo de $50 \%$, indicando um comportamento dúctil em relação aos dois primeiros, conforme pode ser observado na Fig. 6, onde os três últimos pilares foram os que sofreram maior fissuração.

\section{Conclusões}

Com base nos resultados obtidos, observou-se a esperada redução da resistência dos pilares sujeitos a excentricidades. Pode-se concluir que o experimento demonstrou que, apesar de uma redução na resistência, uma maior excentricidade no carregamento pode contribuir para aumentar a ductilidade de pilares de concreto armado sujeitos a flexo-compressão, onde os pilares com as maiores excentricidades (P4 e P5) comportaram-se de forma semelhante a vigas de concreto armado submetidas a esforços de flexão. 
MUNIZ,M.B.S.; SILVA JÚNIOR,F.E.S.D.; SIQUEIRA,G.A.; SILVA,R.J.C. ESTUDO TEÓRICO-EXPERIMENTAL DA RESISTÊNCIA DE PILARES SOB FLEXÃO COMPOSTA NORMAL. $4^{\circ}$ Simpósio Paranaense de Patologia das Construções (40 SPPC), artigo 4SPPC125, pp. 234 - 242, 2019. DOI: 10.4322/2526-7248.045

No entanto, as excentricidades introduzidas no experimento são consideradas altas e não se deve tomar este trabalho como base para dimensionamento de pilares de concreto armado visando a ductilidade, sendo necessários mais estudos para correlacionar excentricidade a ductilidade, pois as conclusões do presente trabalho limitam-se à análise dos pilares aqui estudados.

\section{Agradecimentos}

Os autores gostariam de agradecer à Coordenação de Aperfeiçoamento de Pessoal de Nível Superior (CAPES) pelo apoio financeiro durante o desenvolvimento deste estudo.

\section{Referências}

[1] NBR 6118 (2014) Projeto de estruturas de concreto - Procedimento. Associação Brasileira de Normas Técnicas - ABNT, Rio de Janeiro, Brasil.

[2] Bastos, P. S. dos S. (2015) Pilares de concreto armado - Notas de aula da disciplina de Estruturas de 2015. UNESP, São Paulo, Brasil.

[3] Casagrande, A. F. (2016) Consideração da fluência no cálculo dos efeitos de segunda ordem em pilares de concreto armado. Dissertação (mestrado), Universidade Federal de Santa Catarina - UFSC, Florianópolis, Brasil.

[4] Oliveira, A. P.; Gonçalves, D.; Britto, K.; Campos, N.; Silva, S.; Silva, C.; ... Rocha, J. N. (2019). Análise da estabilidade global das estruturas sob a influência da locação de pilares, Revista Científica Doctum Multidisciplinar, 1(2):1-11.

[5] Alva, G. M. S.; Santos, J. B. dos; Silva, T. J. da. (2018). Influência da rigidez das ligações viga-pilar na análise estrutural de edificíos em concreto armado. RIEM IBRACON Structures and Materials Journal, 11(4):834-855.

[6] Hadhood, A.; Mohamed, H. M.; Benmokrane, B. (2017). Failure envelope of circular concrete columns reinforced with glass fiber-reinforced polymer bars and spirals. ACI Structural Journal, 114(6):1417-1428.

[7] Hales, T. A.; Pantelides, C. P.; Reaveley, L. D. (2017). Analytical buckling model for slender FRP-reinforced concrete columns. Composite Structures, 176:33-42.

[8] NBR 5739 (2007) Concreto - Ensaio de compressão de corpos-de-prova cilíndricos. Associação Brasileira de Normas Técnicas - ABNT, Rio de Janeiro, Brasil.

[9] NBR 7222 (2011) Argamassa e concreto - Determinação da resistência à tração por compressão diametral de corpos-de-prova cilíndricos. Associação Brasileira de Normas Técnicas - ABNT, Rio de Janeiro, Brasil. 